\title{
STUDIES ON LOCATION OF SHEAR WALL IN BUILDINGS FOR STRUCTURAL STABILITY
}

\author{
Sanjeebanee Behera ${ }^{1}$, P.K Parhi ${ }^{2}$ \\ ${ }^{1}$ Post Graduate student in structural engineering, CET Bhubaneswar \\ ${ }^{2}$ Professor, Department of Civil engineering, CET Bhubaneswar
}

\begin{abstract}
In seismic design of multistoried building, shear walls are most common structure adopted to make the structure earthquake resistant. These are constructed to counteract the lateral loads caused by wind load and seismic loads. Shear walls provide adequate stiffness to the structure. So that the lateral drift will be in limits. Generally shear walls are the vertical cantilever which acts as a column.
\end{abstract}

This investigation presents the study and comparison of earthquake behaviour of buildings with and without shear wall using STAAD Pro. In this study, reinforced concrete buildings are analyzed by changing the various position of shear wall with different locations considering various parameters such as story drift, lateral displacement and others.

Keywords: Seismic analysis, Shear wall, Story drift, STAAD Pro V8i. ****.

\section{INTRODUCTION}

Now-a-days multistoried buildings are rapidly constructed everywhere in the world and they are more slender and more sway than earlier buildings. The deformation of tall structures is composed of axial, bending, torsion, transverse shear. In recent period many new concepts and methods are adopted in field of seismic design. In general, RCC structures are constructed to control the lateral displacement. Shear walls are most common structural system which provides lateral stiffness and stability against the lateral loads. In frame structure, the shear walls behaviour is similar to the column which is subjected to combined flexure and axial load. So these are also called flexural members. Shear walls require proper designing and detailing in high seismic regions. Therefore it is necessary to determine the efficient, effective and ideal location of shear wall. This paper represents the analysis of structure with the effect of shear wall position on lateral displacement and story drift in $\mathrm{RC}$ frames. The analysis of shear wall was performed by STAAD Pro V8i using surface elements.

\section{LITERATURE VIEW}

Shear wall system is most significantly used for tall structure in earthquake prone area. So, there are many research work was done in various aspects of shear walls which are as follows:

P.P. Chandurkar et.al. (2013) presented a study on "seismic analysis of RCC building with and without shear wall". The paper determined the lateral displacement, story drift ratio, concrete quantity, total cost, $\%$ of Ast in column required of tenth storied building calculated by placing the shear wall in different location. From that analysis, the building with shear in short span at corner (model 4) is economical as compared to others.
Wakchaure M.R et.al.(2012) presented a study on "earthquake analysis of high rise building with and without infill walls". In this analysis G+9, RCC frame building with the effect of masonry infill wall was studied. The top story displacement of high rise building reduces due to infill walls.

K.LovaRaju et.al.(2015) studied the effective location of shear wall on performance of building frame subjected to earthquake load. The pushover analysis for various models observed the structure with appropriate placed of shear wall has more significant of displacement and base shear.

\section{BUILDING MODELLING}

In the present study, a RCC G+10 storied residential building with 3.5 meters height for each story is modeled. This residential building is designed as a plan of $28.8 \times 27 \mathrm{~m}$ with a lift at centre. M25 grade of concrete and Fe 500 structural steel is used. The structure is supported as fixed at its base. The buildings are modeled and analyzed by using the software STAAD Pro V8i. Models are studied in all four zone comparing story drift, maximum lateral displacement etc. The study of models is designed by placing the shear wall in different location with the thickness of $250 \mathrm{~mm}$.

Model 1- Multistoried building frame without shear wall

Model 2- Multistoried building frame with shear wall at each periphery

Model 3- Multistoried building frame with shear wall at each corner

Model 4- Multistoried building frame with shear in center (at core)

\subsection{Physical Details}

The preliminary data taken for the analysis is as follows:All the dimensions in $\mathrm{mm}$.

- No of stories: $\mathrm{G}+10$ 
- $\quad$ Storey height: $3.5 \mathrm{~m}$

- Beam size in all direction: $250 \times 600 \mathrm{~mm}^{2}$

- Column size: $600 \times 600 \mathrm{~mm}^{2}$

- Thickness of the slab:150mm

\subsection{Building Plans}

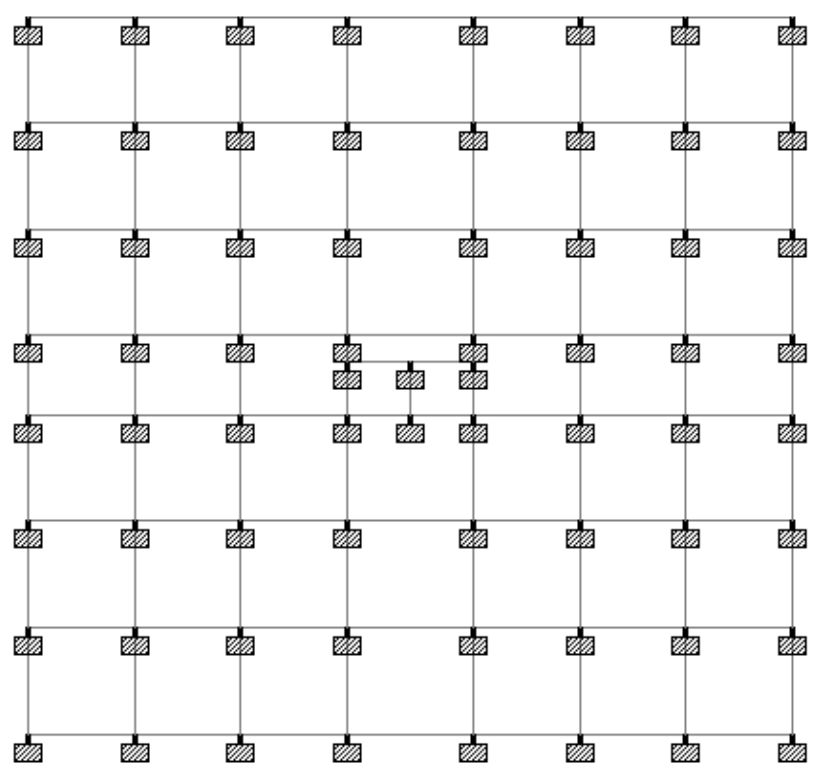

Fig 3.1 Plan of Model-1

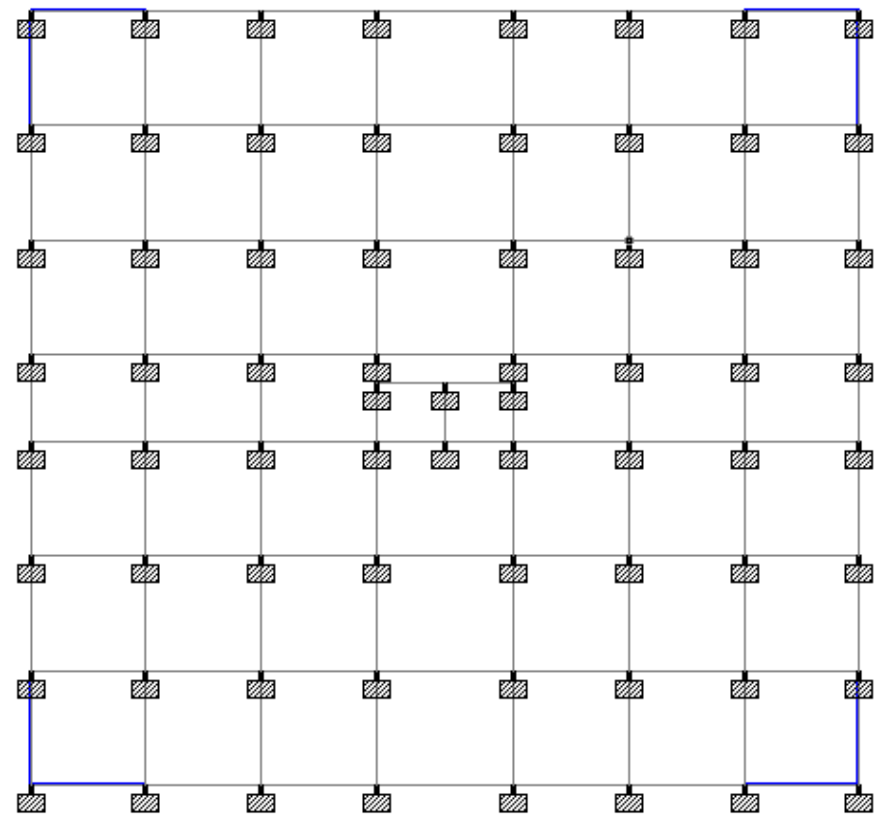

Fig 3.3 Plan of Model-3
- Grade of concrete: M25

- Grade of steel: Fe500

- Density of concrete: $25 \mathrm{KN} / \mathrm{m}^{3}$

- Density of brick: $20 \mathrm{KN} / \mathrm{m}^{3}$

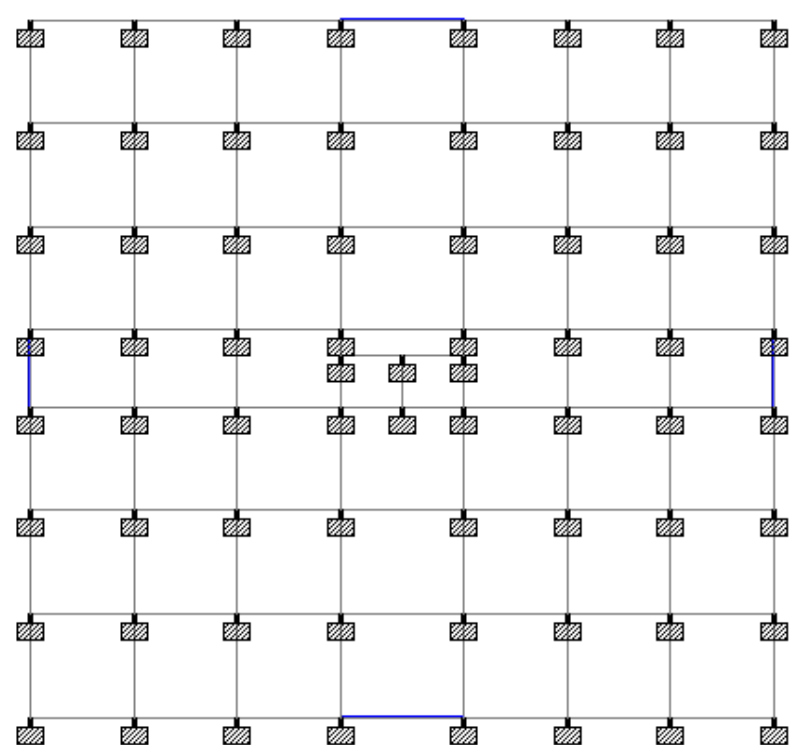

Fig 3.2 Plan of Model-2

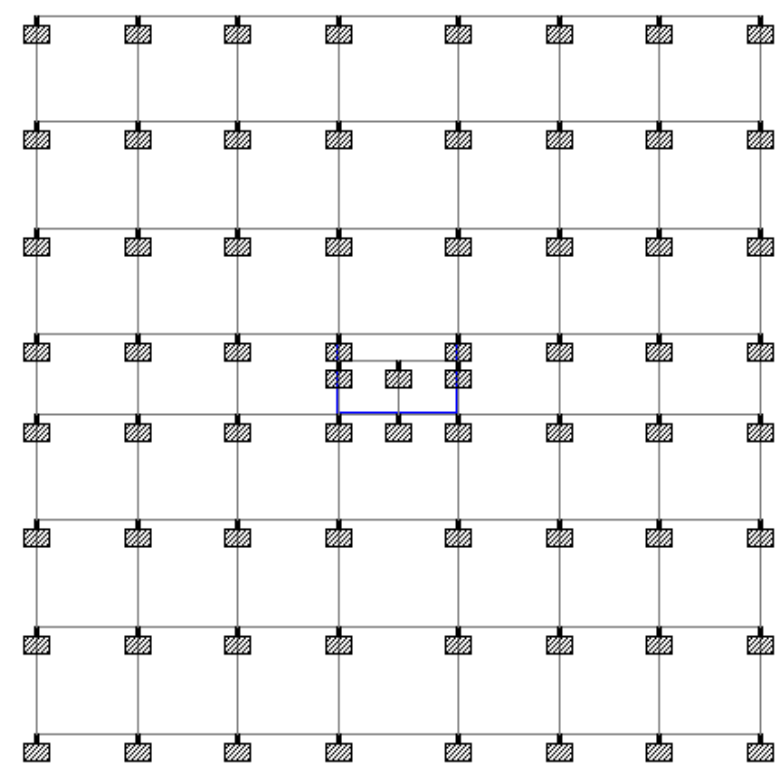

Fig 3.4 Plan of Model-4 


\subsection{D Views of Models}

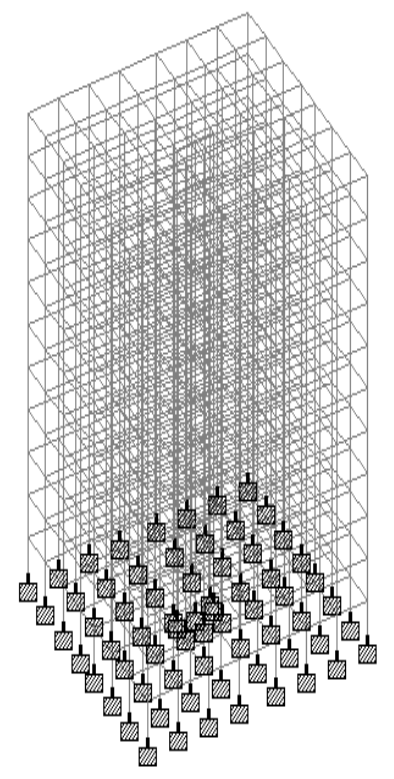

Fig. 3.5 Model 1

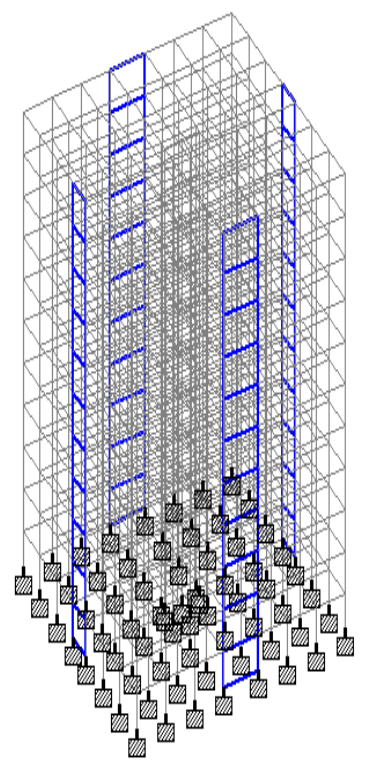

Fig. 3.6 Model 2

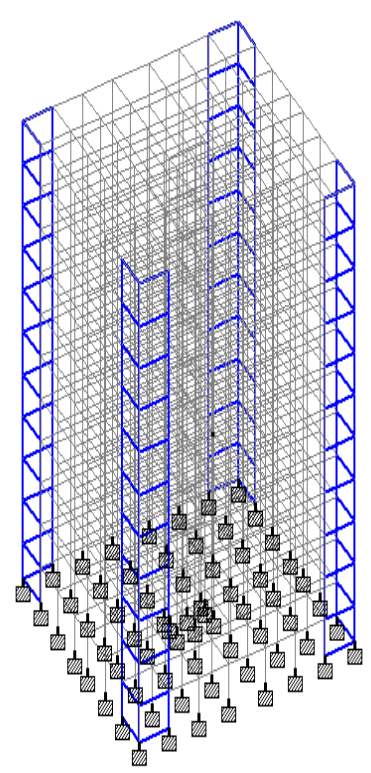

Fig. 3.7 Model 3

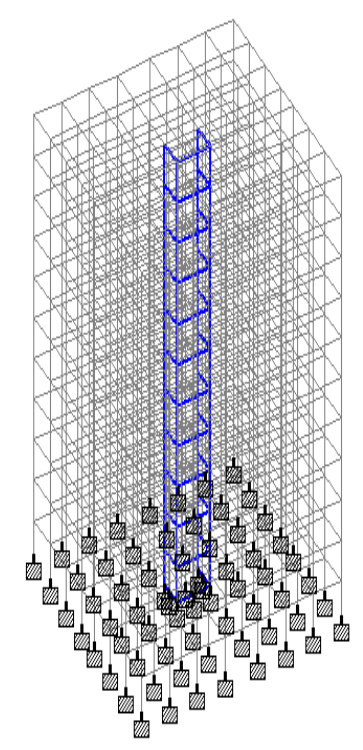

Fig. 3.8 Model 4

\subsection{Methodology}

The loading of building is subjected to dead load and live load as per IS 875 (Part 1) (Part 2): 1987 respectively. As per Indian Code of Practice IS 1893 (Part 1): 2002, IS 875 (Part 3): 1987, design the multistoried residential building against earthquake and wind loads. The member forces are calculated with load combination given in IS 456: 2000. Seismic provision for this building:

- $\quad$ Seismic zone : II, III, IV, V

- Types of the frame : Special Moment Resisting Frame

- $\quad$ Response reduction factor (R) : 5.0

- Importance factor (I) : 1.0

- Soil type : Medium soil

- Damping ratio : $5 \%$

\section{MODEL-1}

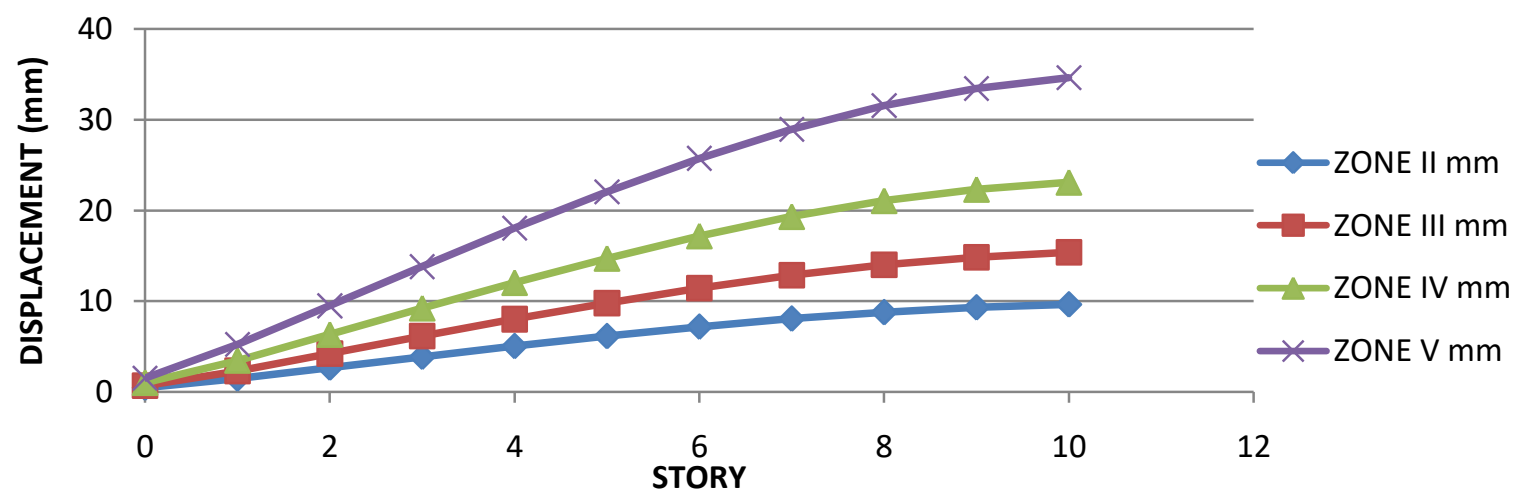

Fig 4.1: Lateral Displacement of MODEL-1 


\section{MODEL-2}

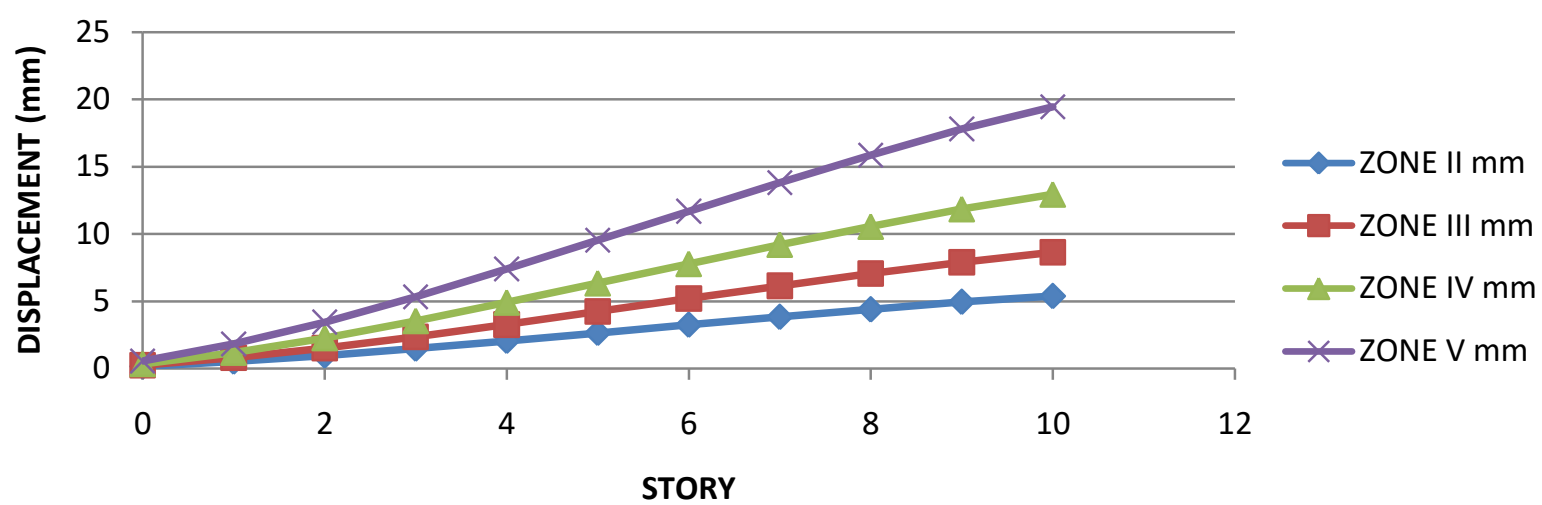

Fig 4.2: Lateral Displacement of MODEL-2

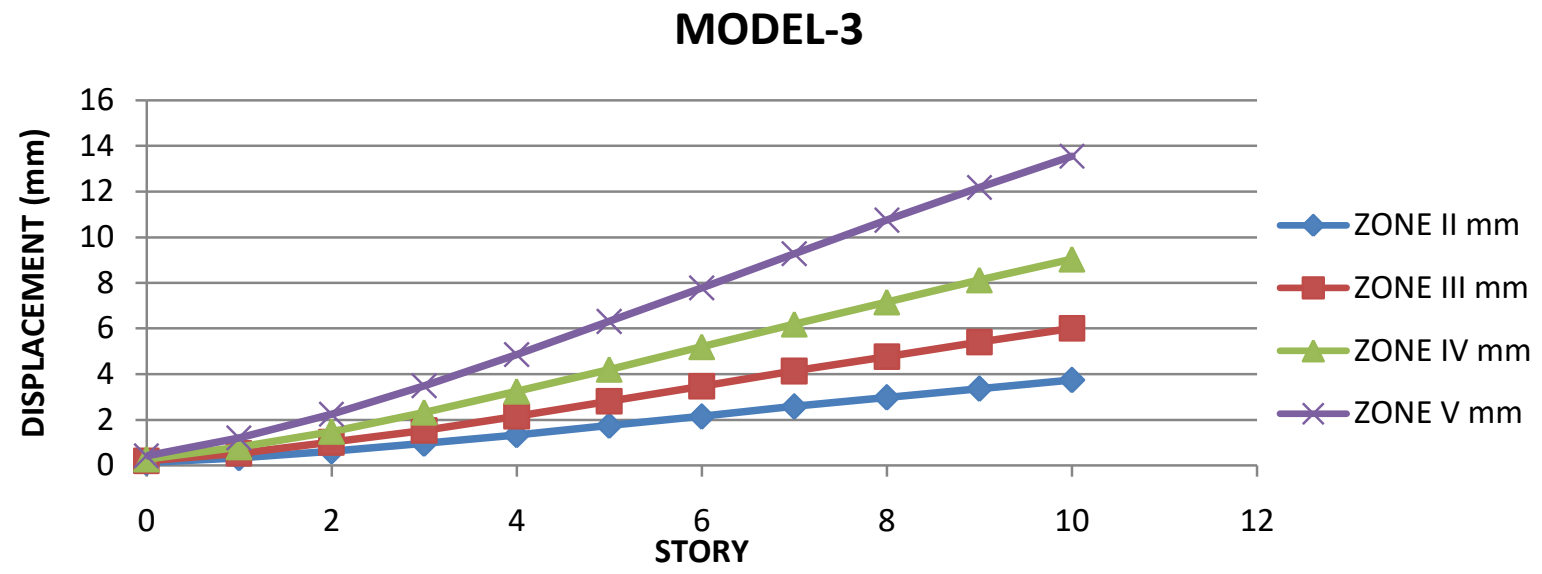

Fig 4.3: Lateral Displacement of MODEL-3

\section{MODEL-4}

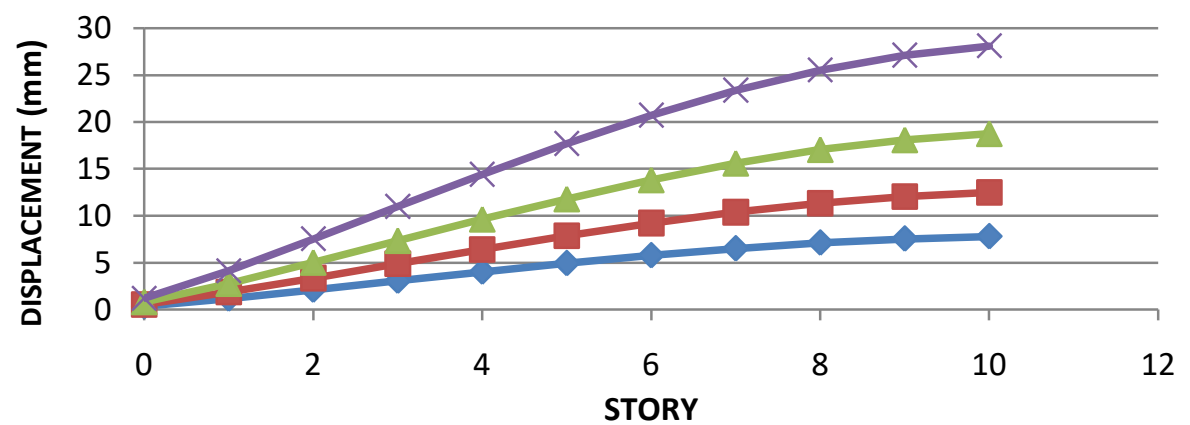

Fig 4.4: Lateral Displacement of MODEL-4

From the observation of lateral displacements of zone II, III, IV, V, Zone V has maximum lateral displacement as seismic intensity is severe in this zone.

\subsection{Displacement Reduction}

As compared to all models, top displacement of model 1 is high. With respect to model 1 , percentage reduction displacement in the top node of model 2, model 3, model 4 are shown in graphs: 
ZONE-2

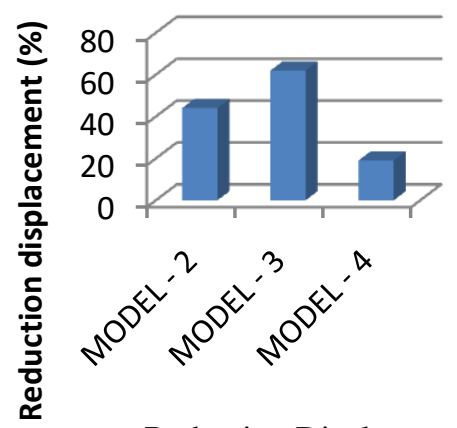

Fig 4.5 Percentage Reduction Displacement at Zone II
ZONE-3

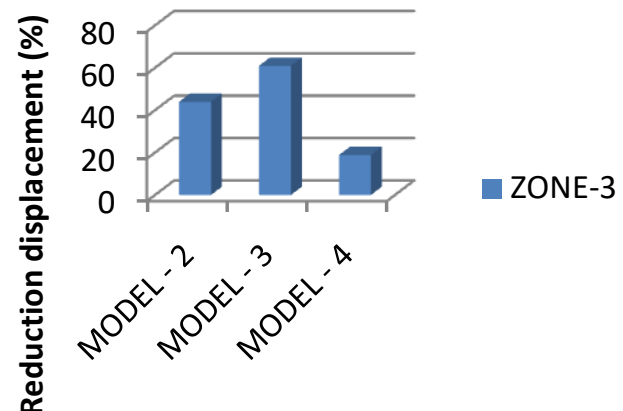

Fig 4.6. Percentage Reduction Displacement at Zone III

\section{ZONE-4}

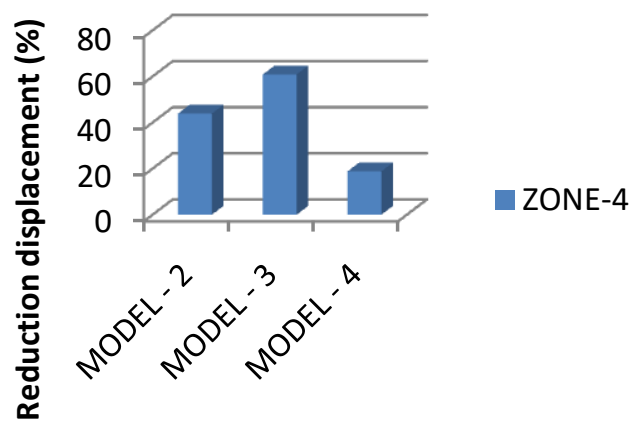

Fig 4.7 Percentage Reduction Displacement at Zone IV

By comparing, the reduction of top displacements of model 3 is high. Displacements of model 2, model 3, model 4 reduced by $43.93 \%, 60.90 \%, 18.87 \%$ respectively. So, it is concluded that shear wall at corner, Model 3 is more effective than other models.

\subsection{Storey Drift}

Story drift is the difference of horizontal displacements between two stories. A preliminary estimate of story drift can be obtained by following.

\section{ZONE-5}

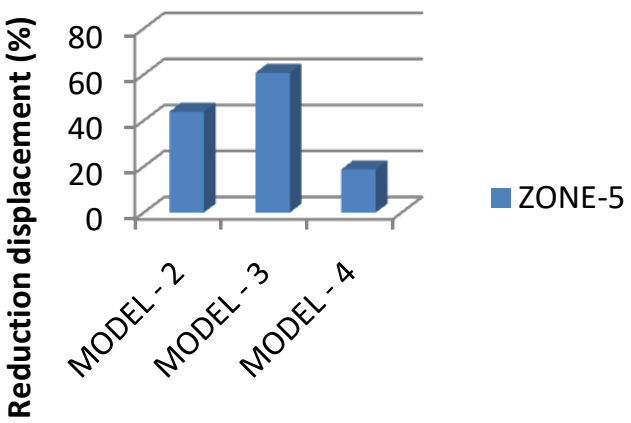

Fig 4.8. Percentage Reduction Displacement at Zone V

Story drift ratio $=\frac{\text { Difference between displacement of two stories }}{\text { height of one story }}$

As per IS: 1893 (Part 1):2002 Cl.7.11.1, the storey drift in any storey due to specified design lateral force with partial load factor of 1.0, shall not exceed 0.004 times the storey height.

Maximum story drift permitted $=0.004 \times 3.5=0.014$

All models are compared and drift values are obtained by using static method. The values are comparing of all models and zone-wise graphs.

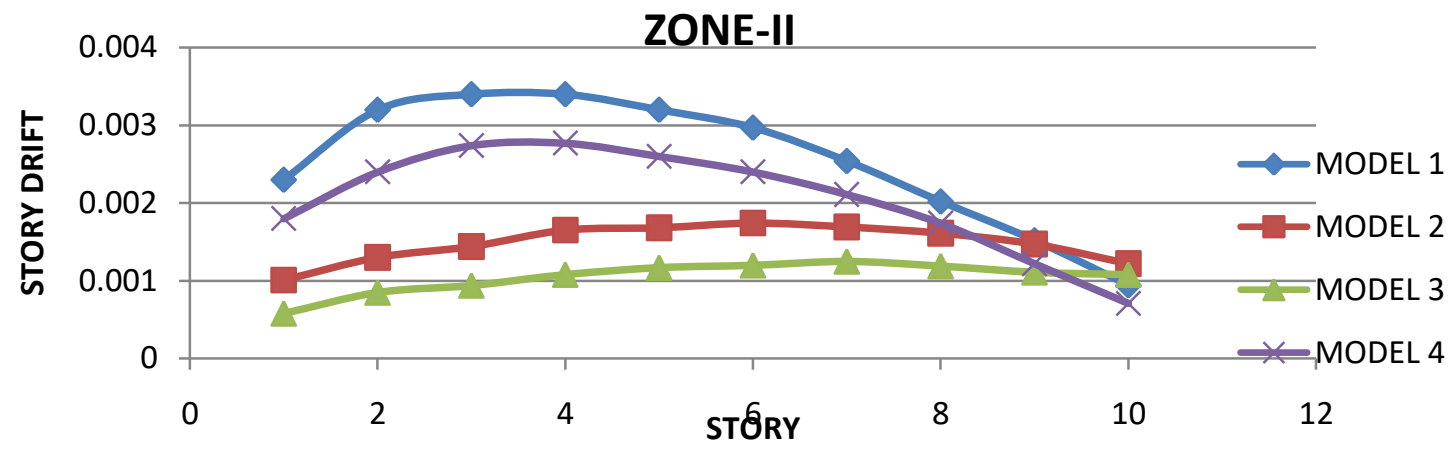

Fig 4.9 Story drift of Zone II 


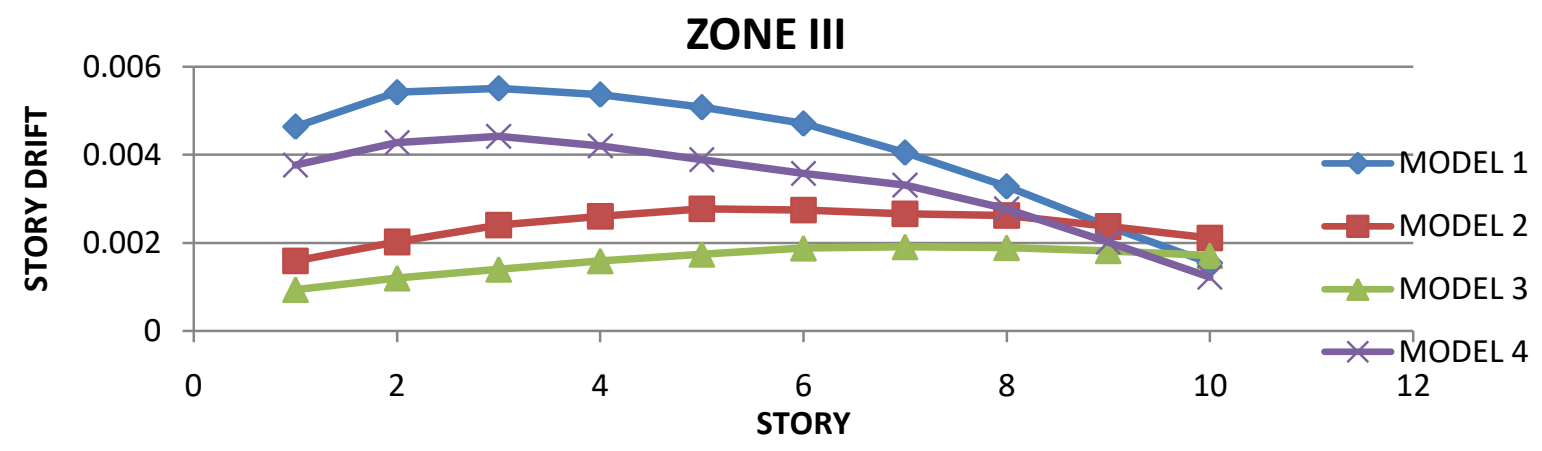

Fig 4.9 Story drift of Zone III

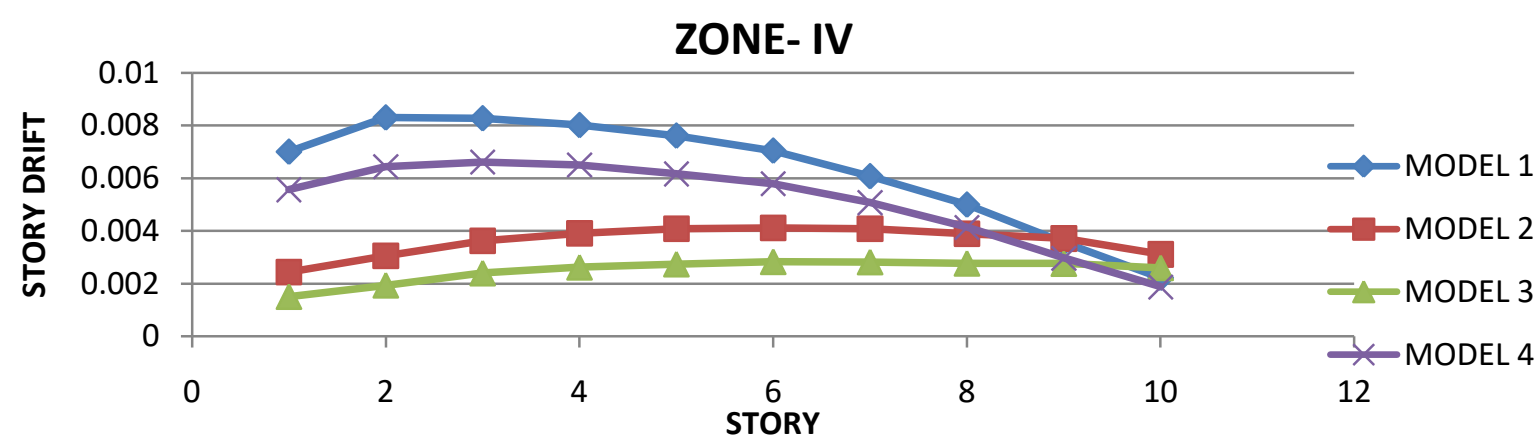

Fig 4.9 Story drift of Zone IV

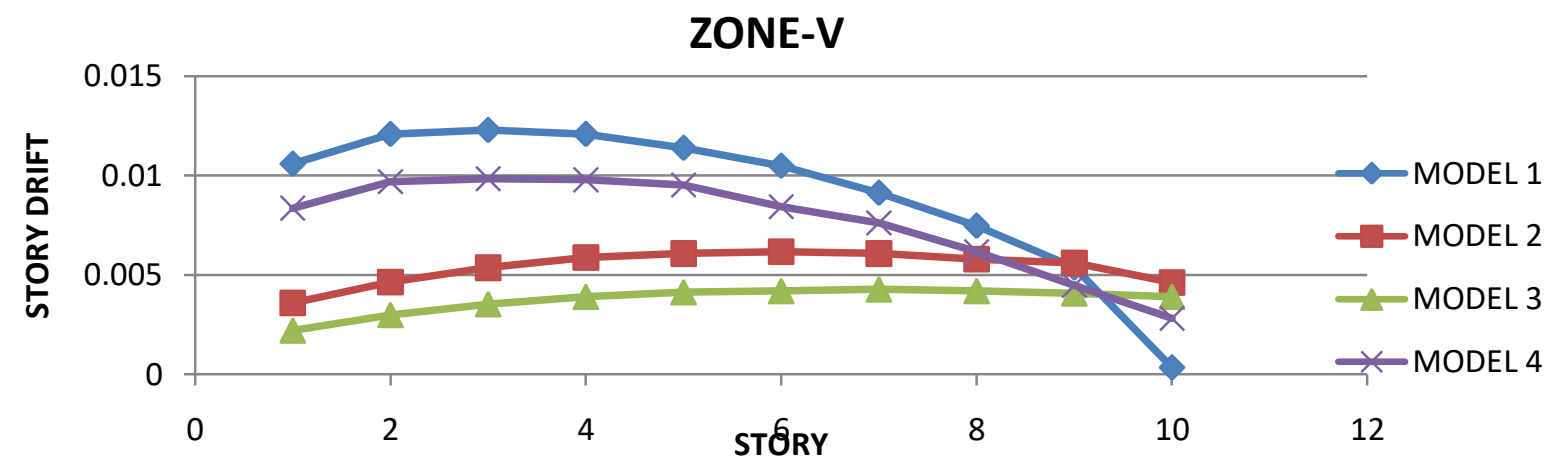

Fig 4.9 Story drift of Zone V

From the observation, building without shear wall (Model 1) has maximum story drift in all zones. Also comparing zonal effect, Zone $\mathrm{V}$ has maximum storey drift. Model 3 has minimum value of story drift as compared to others in all zones.

\section{CONCLUSION}

In the present study, $\mathrm{G}+10$ building has been designed with seismic loading by using equivalent static method. The building is modeled as 3D space frame by STAAD pro software. The dead load, live load, wind loads are calculated by using IS 875(Part 1Part 2 Part 3): 1987 and seismic load as per the IS 1893:2002. Four models are taken into consideration as building frame without shear wall, building frame with side shear wall, building frame with corner shear wall, building frame with shear wall at core. From this we obtained as following:
- In medium to high-rise multistoried buildings lateral displacement is very high if the shear wall is not provided to the buildings. Also axial load and bending moments are maximum on column.

- Presence of shear wall in structure influences the story drift. Model 3 shows the minimum value of story drift. It means if we provide shear wall at corner portion then it can reduce maximum drift to the structure.

- It also indicates shear wall provision along longitudinal and transverse directions reduces the displacement values.

- Reduction percentage of model 3 is more than other placement of shear wall. So corner portion shear wall is the ideal location to make the building earthquake resistant where as model 4 has minimum reduction percentage of displacement. It means shear wall at core or cen- 
tre portion has less effective than other models with shear walls.

- Shear walls are found to be effective, economical and easy for construction as it is RC wall.

\section{REFERENCES}

[1] Agarwal P and Shrikhande M - Earthquake Resistant Design of Structures, New Delhi, PHI learning Private Limited, 2015.

[2] IS $456: 2000$, PLAN AND REINFORCED CONCRETE CODE FOR PRACTICE (Fourth Revision), New Delhi - 110002: Bureau Indian Standards 2000.

[3] IS 875 (Part 1, Part 2, Part 3): 1987, Code of Practice for design loads (other than earthquake) for buildings and structures, New Delhi - 110002: Bureau Indian Standards 1989.

[4] IS 1893(Part 1) : 2002, Criteria for Earthquake Resistant design of structures, Part 1, General Provisions and Buildings (Fifth Revision), New Delhi - 110002: Bureau Indian Standards 2002.

[5] IS 13920: 1993, Ductile detailing of reinforced concrete structures subjected to seismic forces- Code of Practice, New Delhi - 110002: Bureau Indian Standards 2002.

[6] Subramanian N - Design of Reinforced Concrete Structures, PHI Oxford University, New Delhi 110002.

[7] Himalee Rahangdale, S.R.Satone, Design and Analysis of Multistoried Building with Effect of Shear Wall, Vol. 3, Issue 3, May- Jun 2013, 223232.

[8] Shyam Bhat $M$ et.al., "Earthquake behaviour of building with and without shear walls" IOSR Journal of Mechanical and Civil Engineering.

[9] Chandurkar P., Pajgade P. (2013), "Seismic Analysis of RCC Building With and Without Shear wall" International Journal of Modern Engineering Vol. 3, Issue 3, May-June 2013 pp-1805-1810.

[10] Wakchaure M.R., Ped S. P (2012), "Earthquake Analysis of High Rise Building with and without In filled walls" International journal of engineering and innovation technology (IJEIT) Vol. 2, Issue 2, August 2012. 